\title{
CLINICAL OUTCOME OF DIODE LASER USAGE VERSUS CONVENTIONAL SURGICAL TECHNIQUE IN MANAGEMENT OF DELAYED ERUPTED TOOTH
}

\author{
Ramy S Yossif*, Mahmoud T El-Destawy**, Mohamed A El-Patal ${ }^{* * *}$ and Samy Y Elbaiomy ${ }^{* * * *}$
}

\begin{abstract}
This study aimed to evaluate clinical outcome of diode laser usage versus conventional surgical technique in management of delayed erupted tooth. Twenty Egyptian child patients suffering from delayed erupted tooth were participated in this study. Patients were properly assessed for delayed eruption. A periapical x-ray films were taken in order to evaluate the degree of root formation, which were appeared developed by $2 / 3$. The patients were randomly assigned to two groups: Group I, controlled group (10 patients) were received exposure of delayed erupted tooth (DET) by conventional method. Groups II, test group (10 patients) were treated by diode laser. The laser wavelength was $935 \mathrm{~nm}$ and set in a continuous wave mode at a power output of 1.6 watt with a 0.4-mm diameter fiber. Follow up, patients were evaluated clinically: Bleeding assessment and Pain assessment. The findings of the present study demonstrated that laser group showed that VAS score of pain on day 1 and 7 are significantly lower in the laser group as compared to the surgical group. Laser group showed relatively less bleeding than surgical group and the difference was statistically significant.
\end{abstract}

\section{INTRODUCTION}

Failure of teeth to erupt from the gingival tissues at the usual developmental time is called delayed tooth eruption (DTE). DTE is used in cases where eruption is inhibited, causing an interruption in the coordination of tooth formation and tooth eruption. The phenomenon may be local or general, and several etiological factors for retarded eruption have been established ${ }^{(1)}$. The delayed eruption may be due to over-retained primary teeth such as ankylosis and incomplete root resorption. The amount of space available for the succedaneums tooth to erupt and the presence of overlying soft tissue or bone should be considered ${ }^{(2)}$.

Mucosal barrier has also been suggested as an etiologic factor in DTE. Any failure of the follicle of an erupting tooth to unite with the mucosa will entail a delay in the breakdown of the mucosa and constitute a barrier to emergence. Gingival hyperplasia might cause an abundance of dense connective tissue or acellular collagen that can be an impediment to tooth eruption. The progress of treatment is often delayed by the incomplete or late eruption of teeth. We must either wait for the tooth to erupt completely or tissue removal. Exposure of teeth to facilitate eruption can be performed by the diode laser as an alternative to flap surgery ${ }^{(3,4)}$.

One of the benefits of laser use in pediatric dentistry is the selective and precise interaction with diseased tissues. Less thermal necrosis of adjacent tissues is produced with lasers than with electrosurgical instruments. During soft tissue procedures, hemostasis can be obtained without

\footnotetext{
* MS Researcher, Pedodontic and Oral Health Department, Faculty of Dental Medicine, Boys, Cairo, Al Azhar University. ** Lecturer, Department of Oral Medicine, Periodontology, Oral Diagnosis and Oral Radiology, Faculty of Dental Medicine, Boys, Cairo, Al Azhar University.

*** Lecturer, Pedodontic and Oral Health Department, Faculty of Dental Medicine, Boys, Cairo, Al Azhar University. **** Professor, Pedodontic and Oral Health Department, Faculty of Dental Medicine, Boys, Cairo, Al Azhar University.
} 
the need for sutures in most cases. With the benefit of hemostasis during soft tissue treatments, wound healing can occur more rapidly with less post-operative discomfort and a reduced need for analgesics. Little to no local anesthesia is required for most soft-tissue treatments. Reduced operator chair time has been observed when soft tissue procedures have been completed using lasers. Lasers demonstrate decontaminating and bactericidal properties on tissues, requiring less prescribing of antibiotics post-operatively. Lasers can provide relief from the pain and inflammation associated with aphthous ulcers and herpetic lesions without pharmacological intervention ${ }^{(5)}$.

The erbium lasers can remove caries effectively with minimal involvement of surrounding tooth structure because caries affected tissue has a higher water content than healthy tissue. The noise and vibration of the conventional high-speed dental handpiece has been postulated as stimulating discomfort, pain, and anxiety for the pediatric patient during restorative procedures. The noncontact of erbium lasers with hard tissue eliminates the vibratory effects of the conventional high speed handpiece allowing tooth preparations to be comfortable and less anxiety provoking for children and adolescents. Nd: YAG and erbium lasers have been shown to have an analgesic effect on hard tissues, eliminating injections and the use of local anesthesia during tooth preparations ${ }^{(6-9)}$.

With the use of a scalpel for incision or excision, there may be some bleeding, pain, and discomfort during and after surgery. The application of a surgical laser to the soft tissues offers a series of potential advantages, as there is improved vision due to good homeostasis, less mechanical trauma to the soft and hard tissues, elimination of the need for injectable anesthesia and suturing, prevention of local infection, inflammation, and post-operative pain, improved healing, and a shortening of the time needed prior to taking the impression. The acceptance of this simple and comfortable technique by the patient cannot be forgotten ${ }^{(10,11)}$.
In the present study, $935 \mathrm{~nm}$ diode laser system was used and it were set in a continuous wave mode at a power output of 1.6 watt with a $0.4-\mathrm{mm}$ diameter fiber tip. Several advantages of the use of this technique were demonstrated. Among these advantages were the elimination of the need for a flap or suture, no postoperative pain, and rapid healing of the tissues, with the possibility of taking the impression immediately after surgery. This latter advantage was a result of the fact that there was no contamination due to the absence of bleeding and because changes to the tissue margins after surgery were expected to be absent or minimal. In addition, injectable anesthesia was not needed in most cases and the total time required to finish the prosthesis was shortened for the patient.

\section{SUBJECTS AND METHODS}

\section{Study design:}

Intervention randomized clinical trial study.

\section{Study setting and population:}

Twenty Egyptian child patients suffering from delayed erupted tooth were participated in this study. Patients were selected from outpatient clinic of the Department of Pedodontic and Oral Health, Faculty of Dental Medicine, Boys, Cairo, Al-Azhar University.

\section{Eligibility criteria of population:}

(a) Inclusion criteria

- The patients were selected according to the following measures:

(i) Children with delayed erupted tooth.

(ii) Patients were healthy.

(b) Exclusion criteria

- The patients were selected according to the following measures:

(i) Uncooperative children 


\section{Ethical consideration:}

The research protocol was approved by ethical committee, Faculty of Dental Medicine, Boys, Cairo, Al-Azhar University. Patients parents were signed an informed written consent having all the details about the procedure.

\section{Interventions:}

a) Diagnosis of delayed eruption

Patients were properly assessed for delayed eruption. A periapical $\mathrm{x}$-ray films were taken in order to evaluate the degree of root formation, which were appeared developed by $2 / 3$.

(b) The patients were randomly assigned into two groups:

Group I, controlled group: 10 patients were received exposure of DET by conventional method. After the examination, a local anesthetic was administered and then a gingivectomy will be carried out by means of a surgical knife with, in order to expose $2 / 3$ of the crown of tooth and the patients were scheduled for follow-up fig (1).
Groups II, test group: 10 patients were treated by diode laser. The laser wavelength was $935 \mathrm{~nm}$ and set in a continuous wave mode at a power output of 1.6 watt with a $0.4-\mathrm{mm}$ diameter fiber tip ("Doctor Smile", Lambda Laser Products, Vicenza, Italy). The target tissue was dried and topical anesthetic agent was applied to the area with a cotton-tipped applicator and left in place for approximately 3 to 4 minutes. Also, injection of a combination of local anesthetics (Lidocaine $\mathrm{HCl} 2 \%$ ) along with the vasoconstrictor (Epinephrine 1:100,000) produced profound anesthesia in a relatively short amount of time with minimal amount of injection. When the target tissue was sufficiently anesthetized, the tip was directed at an angle of 10 to 20 degrees to the tissue (light contact mode); and was applied continuously with an action similar to brush strokes, "painting away" for approximately 12 Seconds until an acceptable tooth exposure area (occlusal surface) was visible and provided ideal tissue contours and a beveled (Fig. 1).

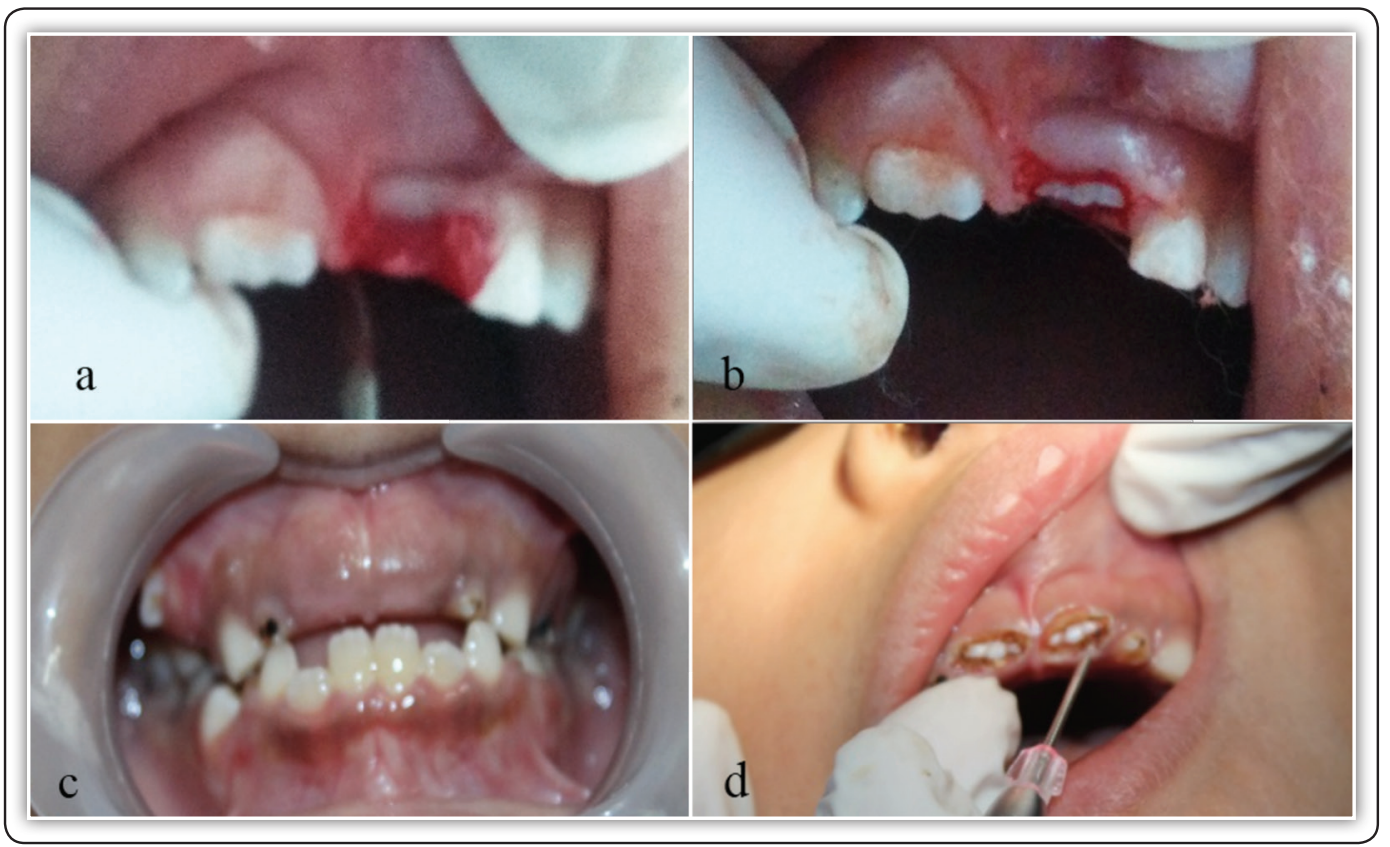

FIG (1) a, Intraoperative surgical exposure with conventional surgery. b, Immediate postoperative. c, Preoperative: child with delayed eruption of the central incisors. d, Intraoperative cutting with diode laser. 
Follow up, patients were evaluated clinically

Bleeding assessment: Postsurgical bleeding was determined in both groups according to the WHO bleeding criteria: (grade 0) no bleeding, (grade 1) bleeding under the skin and petechial class, (grade 2) mild bleeding, (grade 3) gross bleeding, and (grade 4) mortal bleeding or annoying bleeding.

Pain assessment: The pain felt by the patients was evaluated using a visual analog scale (VAS) which was later converted to 11 ranked scores (0: no pain, 10: intolerable pain) as the initial VAS (VAS1)

\section{Statistical analysis:}

The collected data, tabulated and analyzed statistically using statistical package for social science (SPSS) v21 to draw the significance.

\section{RESULTS}

Of 30 subjects, 18 were females and 12 were males with mean age of $11.2 \pm 2.2$. In table (1) and Fig. (6), comparison of bleeding during procedure was assessed among laser group as compared to the surgical group (laser group showed relatively less bleeding than surgical group and the difference was statistically significant $\left(P<0.001^{*}\right)$.

Table (2) and Fig. (7) summarized the Comparison of the mean VAS score of the level of pain, for both groups, and observed on the 1st and the 7th day of the study. The analysis showed that visual analogue scale (VAS) score of pain on day 1 and 7 were significantly lower in the laser group as compared to the surgical group. The difference was statistically significant $\left(P<0.001^{*}\right.$ and $P<0.009^{*}$, respectively). Table (3) and Fig. (3), summarized numbers of analgesics used by surgical group. They were significantly higher $(P<0.058)$ than laser group.

Table (3) and Fig. (8) summarized the comparison between the two studied groups according to analgesics on $1^{\text {st }}$ day. The analysis showed that $53.3 \%$ of patients in surgical group taking analgesics on $1^{\text {st }}$ day. Only $20.0 \%$ of patients in laser group taking analgesics on $1^{\text {st }}$ day. The difference was statistically significant.

TABLE (1) Comparison between the two studied groups according to WHO bleeding score

\begin{tabular}{|c|c|c|c|c|c|c|}
\hline & \multicolumn{2}{|c|}{$\begin{array}{l}\text { Surgical Group } \\
\qquad(n=15)\end{array}$} & \multicolumn{2}{|c|}{$\begin{array}{l}\text { Laser Group } \\
\quad(n=15)\end{array}$} & \multirow{2}{*}{$\mathbf{Z}$} & \multirow{2}{*}{$\mathbf{p}$} \\
\hline & No. & $\%$ & No. & $\%$ & & \\
\hline \multicolumn{7}{|l|}{ WHO bleeding score } \\
\hline 0 & 0 & 0.0 & 15 & 100.0 & \multirow{5}{*}{$5.236^{*}$} & \multirow{5}{*}{$<0.001$} \\
\hline 1 & 13 & 86.7 & 0 & 0.0 & & \\
\hline 2 & 2 & 13.3 & 0 & 0.0 & & \\
\hline Median (Range) & \multicolumn{2}{|c|}{$1.0(1.0-2.0)$} & \multicolumn{2}{|c|}{$0.0(0.0-0.0)$} & & \\
\hline Mean \pm SD & \multicolumn{2}{|c|}{$1.13 \pm 0.35$} & \multicolumn{2}{|c|}{$0.0 \pm 0.0$} & & \\
\hline
\end{tabular}

$Z, p: Z$ and $p$ values for Mann Whitney test for comparing between the two groups.

*: Statistically significant at $p \leq 0.05$ 
TABLE (2) Comparison between the two studied periods according to VAS

\begin{tabular}{|c|c|c|c|c|}
\hline \multirow{2}{*}{ VAS } & \multicolumn{2}{|c|}{ Surgical Group $(\mathrm{n}=15)$} & \multicolumn{2}{|c|}{ Laser Group $(n=15)$} \\
\hline & No. & $\%$ & No. & $\%$ \\
\hline \multicolumn{5}{|l|}{$1^{\text {st }}$ day } \\
\hline 0 & 0 & 0.0 & 7 & 46.7 \\
\hline 1 & 2 & 13.3 & 3 & 20.0 \\
\hline 2 & 8 & 53.3 & 5 & 33.3 \\
\hline 3 & 2 & 13.3 & 0 & 0.0 \\
\hline 4 & 3 & 20.0 & 0 & 0.0 \\
\hline Median (Range) & \multicolumn{2}{|c|}{$2.0(1.0-4.0)$} & \multicolumn{2}{|c|}{$1.0(0.0-2.0)$} \\
\hline Mean \pm SD & \multicolumn{2}{|c|}{$2.4 \pm 0.99$} & \multicolumn{2}{|c|}{$0.87 \pm 0.92$} \\
\hline \multicolumn{5}{|l|}{$7^{\text {th }}$ day } \\
\hline 0 & 8 & 53.3 & 15 & 100.0 \\
\hline 1 & 5 & 33.3 & 0 & 0.0 \\
\hline 2 & 2 & 13.3 & 0 & 0.0 \\
\hline Median (Range) & \multicolumn{2}{|c|}{$0.0(0.0-2.0)$} & \multicolumn{2}{|c|}{$0.0(0.0-0.0)$} \\
\hline Mean \pm SD & \multicolumn{2}{|c|}{$0.6 \pm 0.74$} & \multicolumn{2}{|c|}{$0.0 \pm 0.0$} \\
\hline $\mathbf{p}_{1}$ & \multicolumn{2}{|c|}{$<0.001^{*}$} & \multicolumn{2}{|c|}{$0.009^{*}$} \\
\hline
\end{tabular}

$p_{1}: p$ value for Wilcoxon signed ranks test. For comparing between $1^{\text {st }}$ day and $7^{\text {th }}$ day in each group.

*: Statistically significant at $p \leq 0.05$

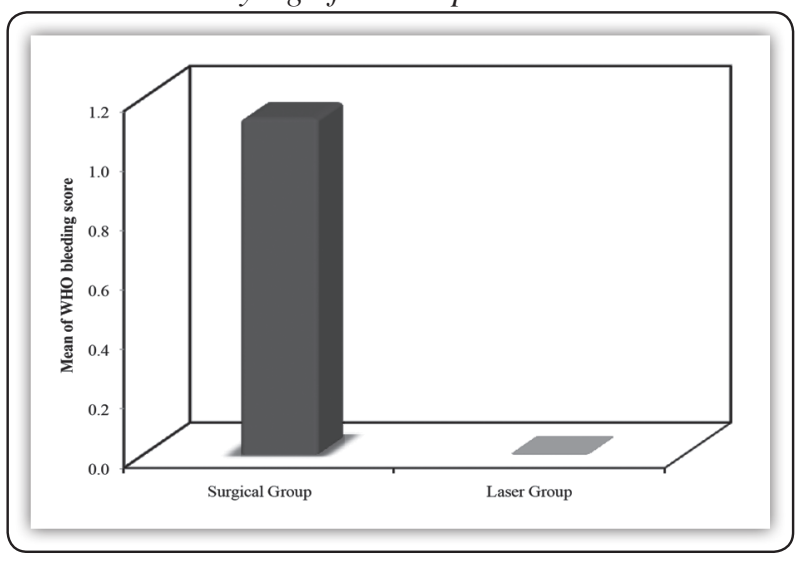

FIG (2) Comparison between the two studied groups according to WHO bleeding score.

TABLE (3) Comparison between the two studied groups according to analgesics on $1^{\text {st }}$ day

\begin{tabular}{|c|c|c|c|c|c|c|}
\hline & \multicolumn{2}{|c|}{$\begin{array}{c}\text { Surgical } \\
\text { Group } \\
(n=15)\end{array}$} & \multicolumn{2}{|c|}{$\begin{array}{l}\text { Laser Group } \\
\quad(n=15)\end{array}$} & \multirow[t]{2}{*}{$\mathbf{C}^{2}$} & \multirow[t]{2}{*}{$\mathbf{p}$} \\
\hline & No. & $\%$ & No. & $\%$ & & \\
\hline \multicolumn{7}{|c|}{ Analgesics On $1^{\text {st }}$ day } \\
\hline Negative & 7 & 46.7 & 12 & 80.0 & \multirow{2}{*}{3.589} & \multirow{2}{*}{0.058} \\
\hline Positive & 8 & 53.3 & 3 & 20.0 & & \\
\hline
\end{tabular}

$c^{2}, p: c^{2}$ and $p$ values for Chi square test for comparing between the two groups.

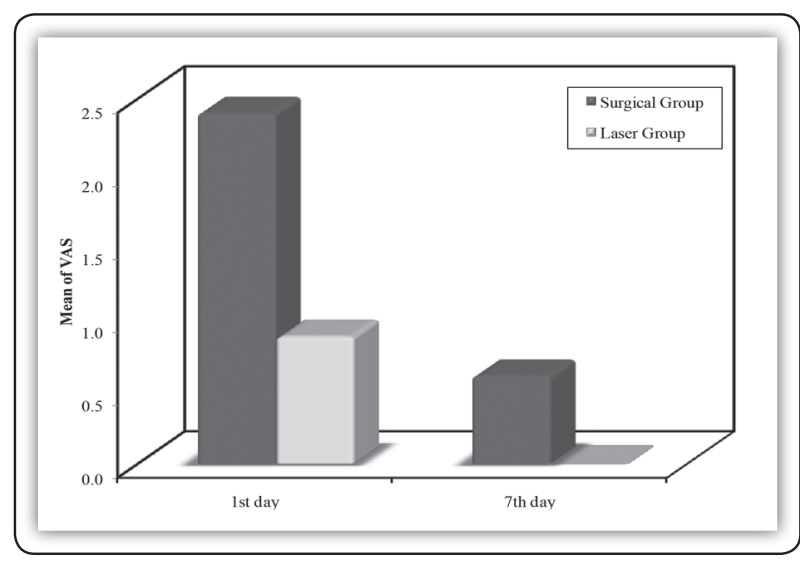

FIG (3) Comparison between the two studied periods according to VAS.

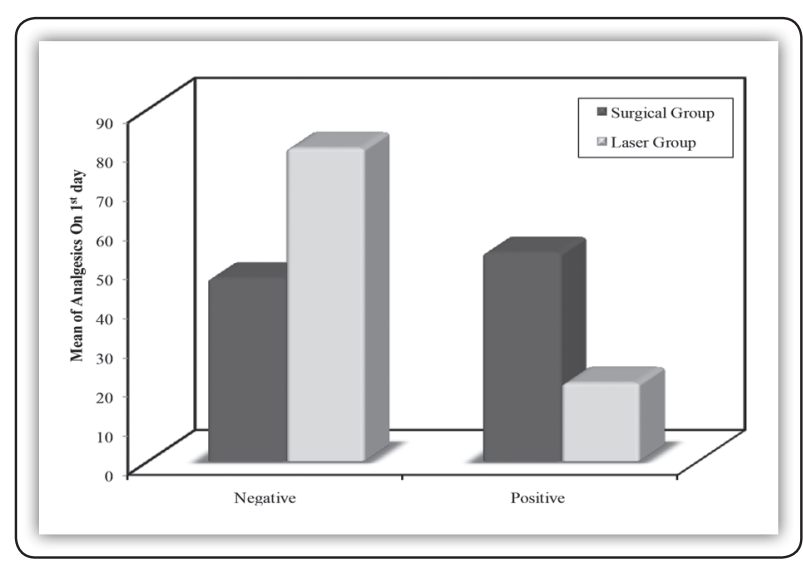

FIG (4) Comparison between the two studied groups according to analgesics on 1 st day. 


\section{DISCUSSION}

The maxillary incisors and canines, often referred to as the 'social six' ${ }^{(16)}$, are the most prominent teeth in an individual's smile. They are also the teeth that are on maximum display during speech in most individuals. The normal eruption, position and morphology of these teeth are crucial to facial esthetics and phonetics, but most parents are anxious about the variation in the timing of the eruption, which is considered as an important milestone during childhood development.

Mucosal barrier has also been suggested as an etiologic factor in DTE. Any failure of the follicle of an erupting tooth to unite with the mucosa will entail a delay in the breakdown of the mucosa and constitute a barrier to emergence. Histologic study has shown differences in the submucosa between normal tissues and tissues with a history of trauma or surgery. Gingival hyperplasia resulting from various causes (hormonal or hereditary causes, vitamin C deficiency, drugs such as phenytoin) might cause an abundance of dense connective tissue or acellular collagen that can be an impediment to tooth eruption ${ }^{(17)}$.

The present study showed that VAS score of pain on day 1 and 7 are significantly lower in the laser group as compared to the surgical group. It has also been observed that the reduction in pain and discomfort levels from the 1st to the 7 th day is much more significant for the laser group. The increased pain perception associated with the scalpel exposure of DET procedures might be attributed to the fact that it is a more intrusive surgical procedure involving blood loss, wide surgical and wound. On the contrary, the decreased pain and discomfort in the laser group might be ascribed to the protein coagulum formed over the wound, which acts like a biological dressing, aids in sealing of the ends of sensory nerves.

Antenucci ${ }^{(18)}$, in agreement with the current study, concluded that the use of the laser in soft tissue management maximize the health of the oral tissues in a minimally invasive manner. Similarly, Kaur, et al ${ }^{(19)}$ compared the postoperative pain by using visual analogue scale in day 1 of diode laser and conventional techniques, after frenectomy surgery, they demonstrated that the patients received laser surgery has less postoperative pain than conventional surgical technique. Moreover, there are many prior studies ${ }^{(20,21)}$ similar to the findings in this study, where the laser was used for frenectomies, ablation of lesions, incisional and excisional biopsies, gingivectomy, gingivoplasty, soft tissue tuberosity reductions, operculectomies, coagulation of graft donor sites and certain crown lengthening procedures, the better results were in favor of laser treatment than surgical technique

The analysis also showed that patients in surgical group taking analgesics on $1^{\text {st }}$ day more than patients in laser group. The difference was statistically significant. The increased pain perception associated with the scalpel exposure of DET procedures might be attributed to the fact that it is a more intrusive surgical procedure involving blood loss, wide surgical and wound, this finding were found to be compatible with a study of Kaur et al ${ }^{(19)}$ who found that patients in surgical group take more analgesics and this finding confirm the results found with VAS.

In the present study, laser group showed relatively less bleeding than surgical group and the difference was statistically significant. This result supports the results found by a study of Ize-Iyamu et al ${ }^{(22)}$ in which they use diode laser in comparison with conventional surgery for management of soft tissue mucogingival problems associated with orthodontic treatment. They showed also less bleeding and also assessed by WHO scale. In agreement with this result there have been a number of studies that corroborated and confirm that lasers cause less bleeding with minimal scarring (23-26) They found that bleeding with laser was no or less with less complication although they use devices with different wave length and types of laser. 
Also, Fornaini et al ${ }^{(26)}$ found that the operating time with the use of the laser reduced as a result of reduced bleeding during surgery and rapid postoperative haemostasis. In general, the present study are compatible with other studies that recorded less bleeding with the use of the laser. A study by Pirnat (27) demonstrated the cutting ability of the soft tissue diode laser with a depth of 2- $6 \mathrm{~mm}$ into the tissues with the sealing of small blood and lymphatic vessels as a result of the heat generated thereby eliminating bleeding and oedema. Also, the findings of the present study compared favorably with a study by Stubinger et al ${ }^{(28)}$ who demonstrated the effect of the laser for various surgical procedures in the oral cavity with excellent effects on the oral soft tissues. They found that excellent intra-operative and postoperative bleeding and pain as a result of the excellent cutting and coagulation abilities of the laser.

The wavelength of this laser is feebly absorbed in water, but extremely absorbed in hemoglobin and other pigments which contributes to their thermal effect. This was the reason that homeostasis occurs. The use of $935 \mathrm{~nm}$ diode laser in this study allowing increased surgical precision and accuracy, thereby reducing unnecessary damage to underlying tissues, and the procedure was with no bleeding in all cases, resulting in improving visualization of the surgical field, eliminating the need for postoperative sutures, and shortening the operation time, probably the efficiency of the laser allows sealing lymphatic and blood vessels.

\section{REFERENCES}

1. Rasmussen P, Kotsaki A. Inherited retarded eruption in the permanent dentition. J Clin Pediatr Dent 1997;21(3): 205-11.

2. Burch J, Ngan P, Hackman A. Diagnosis and treatment planning for unerupted premolars. Pediatr Dent1994; 16(2):89-95

3. Sarver DM, Yanosky M. Principles of cosmetic dentistry in orthodontics: Part 3. Laser treatments for tooth eruption and soft tissue problems. Am J Orthod Dentofacial Orthop 2005; 127:262-4.
4. Suri I, Gagari E, Vastardis H. Delayed tooth eruption: pathogenesis,diagnosis and treatment. A literature review. Am J Dentofac Orthop 2004;126;432-45

5. Olivi G, Genovese MD, Caprioglio C. Evidence-based dentistry on laser paediatric dentistry: Review and outlook. Eur J Paediatr Dent 2009;10(1):29-40.

6. Tanboga I, Eren F, Altinok B, Peker S, Ertugal F. The effect of low level laser therapy on pain during cavity preparation with laser in children. Eur Arch Paediatr Dent 2011;12(2):93-5.

7. Whitters CJ, Hall A, Creanor SL, et al. A clinical study of pulsed Nd:YAG laser induced pulpal analgesia. J Dent 1995;23(3):145-50.

8. Matsumoto K, Hossain M, Hossain MM, Kawano H, Kimura Y. Clinical assessment of Er,Cr:YSGG laser applications for caries removal and cavity preparation in children. Med Laser Appl 2002;20(1):17-21.

9. Den Besten PK, White JM, Pelino JEP, Furnish G, Silveira A, Parkins FM. The safety and effectiveness of an Er:YAG laser for caries removal and cavity preparation in chil-dren. Med Laser Appl 2001;16(3):215-22.

10. Yeh S, Jain K, Andreana S. Using a diode laser to uncover dental implants in second-stage surgery. Gen Dent 2005;53:414-7.

11. Romanos GE. Treatment of periimplant lesions using different laser systems. J Oral Laser Appl 2002;2:75-81.

12. Massoud Seifi, Elahe Vahid-Dastjerdi, Nazila Ameli, Mohammad-Reza Badiee, Farnaz Younessian, Parisa Amdjadi. The $808 \mathrm{~nm}$ laser-assisted surgery as an adjunct to orthodontic treatment of delayed tooth eruption. J Lasers Med Sci 2013; 4:2

13. Webert K, Cook RJ, Sigouin CS, Rebulla P, Heddle NM. The risk of bleeding in thrombocytopenic patients with acute myeloid leukemia. Haematologica. 2006; 91:1530-7

14. Seymour RA, Walton JG. Pain control after third molar surgery. Int J Oral Surg. 1984; 13:457-85.

15. Haraji A, Rakhshan V, Khamverdi N, Alishahi HK. Effects of intra-alveolar placement of $0.2 \%$ chlorhexidine bioadhesive gel on dry socket incidence and postsurgical pain: a double-blind split-mouth randomized controlled clinical trial. J Orofac Pain. 2013; 27:256-62.

16. Pahkala R, Pahkala A, Laine T. Eruption pattern of permanent teeth in a rural community in northeastern Finland. Acta Odontol Scand. 1991; 49:341-9. 
17. Proffit WR, Fields HW. Contemporary orthodontics. $3^{\text {rd }}$ ed. Mosby Inc.; 2000.

18. Antenucci EL. Integration of lasers into a soft tissue management programme. Dent Clin North Am 2000; 44: 811-19

19. Kaur P, Dev YP, Kaushal S, Bhatia A, Vaid R, Sharma R. Management of the upper labial frenum: a comparison of conventional surgical and lasers on the basis of visual analogue scale on patients perception. J Periodontal Med Clin Pract 2014; 01:38-46

20. Fenner J, Martin W, Moseley H, Wheatley DJ. Shear strength of tissue bonds as a function of bonding temperature: A proposed mechanism for laser-assisted tissue welding. Laser Med Sci 1992;7:39-43.

21. Schuller DE. Use of the laser in the oral cavity. Otolaryngol Clin North Am 1990;23:31-42.

22. Ize-iyamu1, b. D. Saheeb2 and b. E. Edetanlen ,Comparing the $810 \mathrm{~nm}$ diode laser with conventional Surgery in orthodontic soft tissue.

23. Pick RM, Pecaro BC. Use of the $\mathrm{CO} 2$ laser in soft tissue dental surgery. Lasers Surg Med 1987;7:207-13. D'
24. Arcangelo C, Di Nardo Di Maio F, Prosperi GD Conte E, Baldi M, Caputi S. A prelimnary study of healing of diode laser versus scalpel incisions in rat oral tissue: a comparison of clinical, histopathological, and immunological results. Oral Surg Oral Med Oral Pathol Oral Radiol Endod 2007;103:764-73.

25. Millard MJ, Mathews L, Aronoff BL, Hults D. Soft tissue studies with $805 \mathrm{~nm}$ diode laser radiation: Thermal effect with contact tips and comparison with effects $1064 \mathrm{~nm}$ Nd:YAG laser radiation. Lasers Surg Med 1993;13: 528-36.

26. Fornaini C, Rocca JP, Bertrand MF, Merigo E, Nammour S, Vescovi P. Nd:YAG and diode laser in the surgical management of soft tissues related to orthodontic treatment. Photomed Laser Surg 2007;25: 381-92.

27. Pirnat S. Versatility of an $810 \mathrm{~nm}$ Diode laser in dentistry: An overview. LAHA 2007; 4:1-9.

28. Stubinger S, Saldamli B, Jurgens P, Ghazal G, Zeilhofer HF. Soft tissue surgery with the diode laser-theoretical and clinical aspects. Schweiz Monatsschr Zahnmed 2006; 116:812-20 